\title{
Composição Química e Contribuição Nutritiva de Cecotrofos de Diferentes Dietas
}

\author{
Augusto Vidal da Costa Gomes ${ }^{1}$, Walter Motta Ferreira ${ }^{2}$
}

\begin{abstract}
RESUMO - Os efeitos de cinco fontes de fibra sobre a produção, composição química e a contribuição nutritiva dos cecotrofos em termos de matéria seca e proteína bruta foram estudados. Quarenta coelhas da raça Nova Zelândia branco foram alojadas em gaiolas metabólicas, por 12 dias, para adaptação às dietas. No 13o dia, para evitar a coprofagia, os animais receberam um colar de madeira por um período de 24 horas, procedendo-se à coleta dos cecotrofos de duas em duas horas. A dieta padrão tinha como principal fonte de fibra o feno de alfafa. As outras dietas foram caracterizadas pela substituição isométrica do feno de alfafa por feno de guandu (Cajanus cajan), palha de feijão, palha e sabugo de milho branco e o feno coast-cross (Cynodon dactylon). Foi observado efeito do tipo de dieta sobre a composição química dos cecotrofos e o teor de PB ingerida por cecotrofia, porém a produção de cecotrofos não diferiu entre dietas.
\end{abstract}

Palavras-chave: coelho, cecotrofos, cecotrofia

\section{Chemical Composition and Nutritive Contribution of Cecothrophes from Different Diets}

\begin{abstract}
The effects of five fiber sources on the production, chemical composition and cecotrophes nutritive contribution on dry matter and crude protein base were studied. Forty White New Zealand female rabbits were housed in metabolic cage for 12 days to adaptation to the diets. In the $13^{\text {th }}$ day, to prevent coprophagy, the animals received a necklace of wood for a period of 24 hours, and the cecotrophes were collected every two hours. The standard diet had the alfalfa hay as a mainly fiber source. The other diets were characterized by isometric replacement of alfalfa hay by pigeon pea hay (Cajanus cajan), bean straw, white corn with cob and husks and coast-cross hay (Cynodon dactylon). Effect of diet type on cecotrophes chemical composition and crude protein content ingested by cecotrophy was observed, however the cecotrophes production was not different among diets.
\end{abstract}

Key Words: rabbit, cecotrophes, cecotrophy

\section{Introdução}

A coprofagia é observada em herbívoros como consequiência da adaptação do processo digestivo de animais de pequeno porte a condições alimentares particularmente difíceis. Estes animais têm, relativamente ao seu peso corporal, necessidades nutritivas muito elevadas, as quais não podem ser supridas com alimentos fibrosos, de baixa digestibilidade, que é naturalmente limitada pela capacidade do seu compartimento de digestão microbiana e/ou pela velocidade do trânsito digestivo.

A coprofagia fornece determinada quantidade de nutrientes sintetizados no ceco e reciclagem de parte do alimento não-digerido, o que implica em melhor utilização do mesmo. O coelho produz dois tipos de fezes; as duras e as moles, ingerindo apenas as últimas. Estas, por terem composição química muito semelhante à do conteúdo do ceco, tem sido, por proposta de EDEN (1940), denominadas de cecotrofos e o fenômeno, cecotrofia.

Alguns trabalhos têm demonstrado que o tipo de fibra pode influenciar a produção e composição quími- ca dos cecotrofos.

Estudando cinco regimes alimentares, PROTO et al. (1968) verificaram que a quantidade diária de cecotrofos eliminados variava conforme a natureza do alimento. CARABAÑO et al.(1988) citam valores de excreção que variam de 14,98 a 29,59 g de matéria seca por dia. FERREIRA (1990), trabalhando com duas fontes de fibra, observou contribuição da matéria seca pelos cecotrofos, em relação à matéria seca ingerida, em torno de 16,5\%, quando utilizou a polpa de beterraba, e de $17,1 \%$, para o bagaço de uva. A contribuição dos cecotrofos em relação à proteína ingerida para os mesmos alimentos foram de 28 e $27 \%$, respectivamente. $\mathrm{O}$ autor cita que a composição química dos cecotrofos em termos de matéria seca (MS) e proteína bruta (PB) foi influenciada em função do tipo da dieta. Conclusões diferentes chegaram CARABAÑO et al. (1989), que estudaram o efeito da dieta sobre a produção e contribuição relativa dos cecotrofos em termos de PB e MS. Os autores substituíram a alfafa por palha de trigo e farelo de girassol e concluíram que a dieta não influiu na produção de cecotrofos e na contribuição em termos de MS e proteína ingerida. 
O objetivo deste trabalho foi avaliar o efeito de cinco fontes de fibra sobre a composição química, produção e contribuição dos cecotrofos em termos de MS e PB.

\section{Material e Métodos}

O experimento foi conduzido no Departamento de Zootecnia da Escola de Veterinária da UFMG. Formulou-se uma dieta padrão, na qual a principal fonte de fibra foi o feno de alfafa. As demais dietas caracterizaram-se pela substituição isométrica do feno de alfafa (FA) por feno de guandu (Cajanus cajan) (FG), palha de feijão (PF), palha e sabugo de milho branco (PSMB) e o feno coast-cross (Cynodon dactylon) (FCC), sendo os demais ingredientes fixos em todas as dietas. Essas dietas foram peletizadas, obtendo-se grânulos com $5 \mathrm{~mm}$ de diâmetro e $10 \mathrm{~mm}$ de comprimento. A fórmula das dietas experimentais e a composição química encontram-se nas Tabelas 1 e 2, respectivamente. Para a realização do experimento, utilizaram-se 40 coelhas da raça Nova Zelândia branco, com peso médio de $2,30 \mathrm{~kg}$, distribuídas em delineamento inteiramente casualizado, com cinco tratamentos e oito repetições. Os animais foram alojados em gaiolas metabólicas e tiveram período de adaptação às dietas de 12 dias, durante o qual se controlou o consumo de ração.

Com o objetivo de evitar a coprofagia, cada animal recebeu no $13^{0}$ dia um colar de madeira medindo $25 \mathrm{~cm}$ de diâmetro, com um orifício central de $7 \mathrm{~cm}$ de diâmetro. O colar foi colocado às 14 h e retirado ao completar 24 horas. Durante esse período, registrouse o consumo de ração e procedeu-se à coleta de cecotrofos de 2 em 2 horas. Os cecotrofos coletados foram acondicionados e congelados a $-10^{\circ} \mathrm{C}$, para posteriores análises químicas. As dietas e os cecotrofos foram submetidos às análises de MS, PB e matéria mineral (MM), de acordo com os métodos da ASSOCIATION OF OFFICIAL ANALYTICAL CHEMISTS - AOAC (1984). A análise estatística foi realizada segundo o programa SAEG (Sistema para análises estatísticas e genéticas) e as médias comparadas pelo teste de DUCAN, em nível de 5\% de probabilidade.

Tabela 1-Dieta experimental usada para coelhos (\%)

Table 1 - Experimental diet used for rabbits (\%)

\begin{tabular}{|c|c|c|c|c|c|}
\hline & $\begin{array}{l}\text { Dieta-padrão (FA) } \\
\text { Standard diet }(A H)\end{array}$ & $\begin{array}{l}\mathrm{FG} \\
\mathrm{PH}\end{array}$ & $\begin{array}{l}\mathrm{PF} \\
B S\end{array}$ & $\begin{array}{l}\text { PSMB } \\
S C W C\end{array}$ & $\begin{array}{l}\mathrm{FCC} \\
\mathrm{CCH}\end{array}$ \\
\hline Feno de alfafa (FA) & 30,0 & - & - & - & - \\
\hline Alfafa hay $(A H)$ & & & & & \\
\hline $\begin{array}{l}\text { Feno de guandu }(\mathrm{FG}) \\
\text { Pigeon pea hay }(P H)\end{array}$ & - & 30,0 & - & - & - \\
\hline $\begin{array}{l}\text { Palha de feijão }(\mathrm{PF}) \\
\text { Bean straw }(B S)\end{array}$ & - & - & 30,0 & - & - \\
\hline $\begin{array}{l}\text { Palha e sab. de milho branco (PSMB) } \\
\text { Whole white corn cob with husk (SCWC) }\end{array}$ & ) & - & - & 30,0 & - \\
\hline $\begin{array}{l}\text { Feno de coast-cross (FCC) } \\
\text { Coast-cross hay }(\mathrm{CCH})\end{array}$ & - & - & - & - & 30,0 \\
\hline $\begin{array}{l}\text { Farelo de soja } \\
\text { Soybean meal }\end{array}$ & 15 & 15 & 15 & 15 & 15 \\
\hline $\begin{array}{l}\text { Milho } \\
\text { Corn }\end{array}$ & 30 & 30 & 30 & 30 & 30 \\
\hline $\begin{array}{l}\text { Farelo de trigo } \\
\text { Wheat bran }\end{array}$ & 22 & 22 & 22 & 22 & 22 \\
\hline $\begin{array}{l}\text { Calcário } \\
\text { Limestone }\end{array}$ & 0,5 & 0,5 & 0,5 & 0,5 & 0,5 \\
\hline $\begin{array}{l}\text { Fosfato bicálcico } \\
\text { Dicalcium phosphate }\end{array}$ & 0,5 & 0,5 & 0,5 & 0,5 & 0,5 \\
\hline $\begin{array}{l}\text { Óleo vegetal } \\
\text { Vegetal oil }\end{array}$ & 1.0 & 1.0 & 1.0 & 1.0 & 1.0 \\
\hline $\begin{array}{l}\text { Sal } \\
\text { Salt }\end{array}$ & 0,5 & 0,5 & 0,5 & 0,5 & 0,5 \\
\hline $\begin{array}{l}\text { Supl. vitamínico e mineral } \\
\text { Vitamin - mineral mix }^{1}\end{array}$ & 0,5 & 0,5 & 0,5 & 0,5 & 0,5 \\
\hline
\end{tabular}


Tabela 2 - Composição química das dietas experimentais (\%)

Table 2 - Chemical composition of the experimental diets

\begin{tabular}{|c|c|c|c|c|c|}
\hline & $\begin{array}{c}\text { Dieta-padrão (FA) } \\
\text { Standart-diet }(A H)\end{array}$ & $\begin{array}{l}\text { FG } \\
P H\end{array}$ & $\begin{array}{l}\mathrm{PF} \\
B S\end{array}$ & $\begin{array}{l}\mathrm{PSMB} \\
S C W C\end{array}$ & $\begin{array}{l}\mathrm{FCC} \\
\mathrm{CCH}\end{array}$ \\
\hline Matéria seca & 88,76 & 89,57 & 88,85 & 88,41 & 88,78 \\
\hline Dry matter & & & & & \\
\hline $\begin{array}{l}\text { Fibra em detergente ácido } \\
\text { Acid detergent fiber }\end{array}$ & 14,66 & 18,72 & 19,36 & 16.02 & 15,97 \\
\hline $\begin{array}{l}\text { Lignina } \\
\text { Lignin }\end{array}$ & 4,54 & 5,71 & 4,83 & 2,72 & 3,36 \\
\hline $\begin{array}{l}\text { Energia digestível }(\mathrm{Mcal} / \mathrm{kg})^{1} \\
\text { Digestible energy }(\text { Mcal/kg })^{1}\end{array}$ & 2,49 & 2,41 & 2,32 & 2,44 & 2,42 \\
\hline $\mathrm{Ca}$ & 1,06 & 1,13 & 1,19 & 0,83 & 1,05 \\
\hline $\begin{array}{l}\text { P total } \\
\text { Total P }\end{array}$ & 0,69 & 0,69 & 0,60 & 0,57 & 0,58 \\
\hline
\end{tabular}

${ }^{1}$ Valor calculado ( De BLAS et al., 1984a,b).

${ }^{1}$ Calculated value.

\section{Resultados e Discussão}

A composição química dos cecotrofos encontrase na Tabela 3. Observou-se efeito $(\mathrm{P}<0,05)$ do tipo de dieta sobre a composição química dos cecotrofos.

A substituição do FA por PSMB e FCC proporcionou aumento significativo no teor de MS dos cecotrofos. Estes resultados contrariam as conclusões de CUNHA (1988) e PÉREZ de AYALA (1989), que observaram aumento no teor de MS dos cecotrofos em dietas que continham fontes de fibras mais lignificadas, o que não ocorreu neste trabalho, pois estas dietas foram as que apresentaram os menores teores de lignina. Em relação ao teor de PB e MM, a dieta à base de alfafa apresentou valores superiores em torno de 5 e $22 \%$, respectivamente, em relação aos demais tratamentos, sendo que a matéria orgânica (MO) apresentou comportamento inverso.

A Tabela 4 mostra as médias encontradas para consumo de ração, produção de cecotrofos e contribuição de princípios nutritivos pelos cecotrofos.

Constatou-se que houve diferenças $(\mathrm{P}<0,05)$ para o consumo de proteína bruta e, apesar de não ter ocorrido diferença significativa, a dieta de FG proporcionou consumo $14 \%$ superior à dieta padrão; o inverso ocorreu com à dieta de PSMB, que apresentou o menor consumo $(27,46 \%)$, o que, em parte, pode ser atribuído ao consumo de matéria seca, embora esta variável não tenha apresentado diferenças estatísticas entre tratamentos. A produção e o fornecimento de MS pelos cecotrofos não foram influenciados pelo tipo de dieta. Entretanto, a contribuição de $\mathrm{PB}$ pelos cecotrofos em relação ao consumo diário de proteína foi afetado significativamente $(\mathrm{P}<0,05)$ pelo tipo de dieta, obtendo-se o valor mais elevado $(28,55 \%)$ para a dieta de PF. Segundo vários autores (GIDENNE, 1987; CARABAÑO et al. 1988), em dietas mais energéticas, parece que a contribuição de MS e PB pelos cecotrofos diminui em relação a dietas menos energéticas, o que não ocorreu neste trabalho para os valores de MS, porém, em relação ao teor de PB, observou-se este efeito, pois a dieta de PF foi a que apresentou o menor valor energético.

Quanto à produção de cecotrofos, FRAGA et al. (1989) e CARABAÑO et al.(1989) não observaram efeito da fonte de fibra sobre a produção de cecotrofos, o que está de acordo com os resultados obtidos neste trabalho. Os valores obtidos estão próximos aos citados por FERREIRA (1990), cujos valores oscilaram de 15,1 a 19,9 g de MS/dia, porém são superiores aos relatados por PÉREZ de AYALA (1989).

A contribuição em termos de MS, também, se aproxima dos valores citados por FERREIRA (1990), no entanto, o autor relata que a quantidade de proteína fornecida pelos cecotrofos em relação à proteína ingerida ficou em torno de $28 \%$, sendo, portanto, superior à média obtida neste trabalho, $23 \%$, a qual se aproxima do valor citado por CARABAÑO et al. (1989), que utilizaram uma dieta com composição química próxima à das dietas utilizadas neste trabalho e observaram que os cecotrofos contribuíram com $21 \%$ PB ingerida. Já FRAGA et al. (1991), ao trabalharem com cinco fontes, observaram valores inferiores, obtendo, em média, valores de 9 e 13\%, respectivamente, para o teor de MS e PB. Os dados mostram que, em um período de 24 horas, ocorreu reciclagem média de 19,9 g MS e 5,21 g PB. Estes valores são superiores aos obtidos por OGUNDUN et 
Tabela 3 - Composição química (\%) dos cecotrofos (\% MS)

Table 3 - Chemical composition (\%) of cecotrophes (\% DM)

\begin{tabular}{lcccccc}
\hline & \multicolumn{7}{c}{ Dieta } \\
& FA & FG & PF & Diet & & \\
& $A H$ & $P H$ & $B S$ & PSB & FCC & $(C V \%)$ \\
\hline $\begin{array}{l}\text { Matéria seca } \\
\begin{array}{l}\text { Dry matter } \\
\text { Proteína bruta }\end{array}\end{array}$ & $25,08^{\mathrm{b}}$ & $26,69^{\mathrm{ab}}$ & $26,39^{\mathrm{ab}}$ & $27,44^{\mathrm{a}}$ & $27,54^{\mathrm{a}}$ & $(5,72)$ \\
$\begin{array}{l}\text { Crude protein } \\
\text { Matéria orgânica }\end{array}$ & $29,66^{\mathrm{a}}$ & $26,78^{\mathrm{bc}}$ & $28,40^{\mathrm{ab}}$ & $25,30^{\mathrm{c}}$ & $25,34^{\mathrm{c}}$ & $(6,12)$ \\
$\begin{array}{l}\text { Organic matter } \\
\text { Matéria mineral }\end{array}$ & $87,95^{\mathrm{c}}$ & $89,89^{\mathrm{b}}$ & $89,99^{\mathrm{ab}}$ & $90,64^{\mathrm{a}}$ & $90,01^{\mathrm{ab}}$ & $(0,74)$ \\
Ash & $12,04^{\mathrm{a}}$ & $10,10^{\mathrm{b}}$ & $10,01^{\mathrm{bc}}$ & $9,35^{\mathrm{c}}$ & $9,98^{\mathrm{bc}}$ & $(6,53)$ \\
\hline
\end{tabular}

Médias, na linha, seguidas de letras diferentes são diferentes $(\mathrm{P}<0,05)$.

Means, within a row, followed by different letters are different $(P<.05)$

Tabela 4 - Consumo de ração (g MS/dia), consumo de proteína bruta (g/dia),produção de cecotrofos (g MS/ dia) e contribuição de princípios nutritivos pelos cecotrofos

Table 4 - Feed intake (g DM/day), intake protein (g/day), cecotrophes production (g DM/day) and contribuition nutrients by cecotrophes

\begin{tabular}{|c|c|c|c|c|c|c|}
\hline \multirow{3}{*}{$\begin{array}{l}\text { Variável } \\
\text { Variable }\end{array}$} & \multicolumn{6}{|c|}{$\begin{array}{l}\text { Dieta } \\
\text { Diet }\end{array}$} \\
\hline & FA & FG & $\mathrm{PF}$ & PSMB & FCC & $(\mathrm{CV} \%)$ \\
\hline & $A H$ & $\mathrm{PH}$ & $B S$ & $S C W C$ & $\mathrm{CCH}$ & \\
\hline $\begin{array}{l}\text { Consumo de matéria seca } \\
\text { Dry matter Intake }\end{array}$ & $91,67^{\mathrm{a}}$ & $109,26^{\mathrm{a}}$ & $101,67^{\mathrm{a}}$ & $84,95^{\mathrm{a}}$ & $90,22^{\mathrm{a}}$ & $(33,05)$ \\
\hline $\begin{array}{l}\text { Consumo de proteína bruta } \\
\text { Crude protein intake }\end{array}$ & $18,28^{a b}$ & $20,85^{\mathrm{a}}$ & $16,32^{\mathrm{ab}}$ & $13,26^{b}$ & $15,09^{b}$ & $(31,63)$ \\
\hline $\begin{array}{l}\text { Produção de cecotrofos } \\
\text { Cecotrophes production }\end{array}$ & $18,25^{\mathrm{a}}$ & $21,16^{\mathrm{a}}$ & $22,96^{\mathrm{a}}$ & $17,20^{\mathrm{a}}$ & $16,39^{a}$ & $(40,84)$ \\
\hline $\begin{array}{l}\text { Contribuição de MS } \\
\text { pelos cecotrofos }^{1}(\%) \\
\text { DM contribuition } \\
\text { bv cecotronhes } 1\end{array}$ & $16,77^{\mathrm{a}}$ & $16,30^{\mathrm{a}}$ & $18,48^{\mathrm{a}}$ & $16,21^{\mathrm{a}}$ & $15,34^{\mathrm{a}}$ & $(20,48)$ \\
\hline $\begin{array}{l}\text { Contribuição de } \mathrm{PB} \\
\text { pelos cecotrofos }^{1}(\%) \\
\text { CP contribuition } \\
\text { by cecotrophes }^{1}\end{array}$ & $22,83^{\mathrm{b}}$ & $21,35^{\mathrm{b}}$ & $28,55^{\mathrm{a}}$ & $24,49^{b}$ & $21,56^{\mathrm{b}}$ & $(18,61)$ \\
\hline $\begin{array}{l}\text { Médias, na linha, seguidas } \\
\text { Consumo diário do nutriente } \\
\text { dos cecotrofos } \times 100 \text {. } \\
\text { Means, within a row, followed by }\end{array}$ & $\begin{array}{l}\text { ras } d \\
\text { cecoti }\end{array}$ & $\begin{array}{l}\text { S são } \\
\text { nsumo }\end{array}$ & $\begin{array}{l}\text { es }(P<0 \\
\text { do nutri } \\
5) \text {. }\end{array}$ & ação + & o diár & nutriente \\
\hline
\end{tabular}

al. (1991), que citam contribuição nutritiva pelos cecotrofos em termos de MS e PB, em um período de 24 horas, de 13,3 e 3,4 g, respectivamente. Estas variações citadas podem ter ocorrido devido à natureza das dietas.

\section{Conclusões}

A fonte de fibra influenciou a composição química dos cecotrofos, bem como o fornecimento de proteína bruta ingerida, por intermédio da coprofagia.

\section{Referências Bibliográficas}

ASSOCIATION OF OFFICIAL ANALYTICAL CHEMISTS - AOAC. 1984. Official methods of analysis. 14. ed. Washington D.C. 1141p.

CARABAÑO, R., FRAGA, M.J., SANTOMÁ, G. et al. 1988. Effect of diet on composition of cecal contents and on excretion and composition of soft and hard feces or Rabbits. J. Anim. Sci., 66(4):901-910.

CARABAÑO, R., FRAGA, M.J. 1989. Coprofagia. In: De BLAS, J.C. (Ed.) Alimentación del conejo. Madrid: Ediciones Mundi-Prensa, 2.ed. p.15-27. 
Rev. bras. zootec.

CUNHA, L.A.L.F. Os constituintes da parede celular no processo digestivo do coelho. Lisboa: ISATUL, 1988. 359p. Tese (Doutorado) - Universidade Técnica de Lisboa, 1988.

De BLAS, J.C., RODRIGUEZ, J.M., SAMTOMÁ, G. et al. 1984a. The nutritive values of feeds for grwoing fattening rabbits. 1- Energy evaluation. J. Apll. Rabbit Res., 7(2):72-74.

De BLAS, J.C., FRAGA, M.J., RODRIGUEZ, J.M. et al. 1984b. The nutritive value of feeds for growing fattening rabbits. 2 . Protein evaluation. J. Appl. Rabbit Res., 7(3):97-100.

EDEN, A. 1940. Coprophagy in the rabbit: origin of nigth faeces. Nature, 145:628-629.

FERREIRA,W.M. Efecto de la sustitucion parcial de heno de alfafa por orujo de uva o pulpa de remolacha sobre utilizacion de la dieta y los rendimentos productivos en conejos en crecimiento. Madrid: UPM, 1990. 251p. Tese (Doutorado) - Universidade Politécnica de Madrid, 1990.

FRAGA, M.J. 1989. Necessidades de nutrientes. In: De BLAS, J.C. (Ed.)Alimentación del conejo. Madrid, Ediciones MundiPrensa. 2.ed. p.61-74.

FRAGA, M.J., PÉREZ de AYALA, P., CARABÑO, R. et al. 1991. Effect of type of fiber on the rate of passage and on the contribution of sof feces to nutrient intake of finishing rabbits. J. Anim. Sci., 69(4):1566-1574.
GIDENE, T. 1987. Influence de la teneur en lignines des aliments sur la composition des digesta et la production de caecotrophes chez le laperau. Ann. Zootech., 36(1):85-89.

OGUNDUN, W., ADUKU, A.O., OKOH, P.N. 1991. Effect of cassava based diet and day period on the quantity and quality of cecotrophes produced by rabbits. J. Appl. Rabbit Res., 14(2):105-108.

PÉREZ de AYALA , P.M. Utilization de destintos tipos de fibra por los conejos en cebo. Madrid: UPM, 1989. 115p. Tese (Doutorado), Universidade Politécnica de Madrid, 1989.

PROTO, V. et al. 1968. La coprofagia del coniglio sottaporto a different diete. Prod. Anim., 7:157-171.

Recebido em: 28/07/98

Aceito em: 05/07/99 